\title{
Turkish Foreign Policy in South Caucasus and Its Impact in Iran-Azerbaijan Relationship
}

\author{
Masoumeh Rad Goudarzi ${ }^{1}$, Abdollah Baei Lashaki ${ }^{2} \&$ Samereh Fasihi Moghaddam Lakani ${ }^{3}$ \\ ${ }^{1}$ Assistant Professor of Political Science, Department of Political Science, Faculty of Humanity, University of \\ Guilan, Iran \\ ${ }^{2}$ Master of International Relationship, Independent Researcher \\ ${ }^{3}$ Master of International Relationship, Independent Researcher \\ Correspondence: Masoumeh Rad Goudarzi, Department of Political Science, Faculty of Humanity, University of \\ Guilan, 4199843653, Tehran Road, Rasht, Iran. Tel: 98-911-150-0260. E-mail: fr.raad1@gmail.com
}

Received: January 19, 2015 Accepted: January 30, 2015 Online Published: February 27, 2015

doi:10.5539/jpl.v8n1p122 URL: http://dx.doi.org/10.5539/jpl.v8n1p122

\begin{abstract}
The collapse of the Soviet Union has been one of the most important events of the twentieth century. As a result of the collapse, Iran became the neighbor of the new countries. Azerbaijan is one of the countries, which have historical, cultural and religious commonalities with Iran. Despite the great sharing that exists between Iran and Azerbaijan, relations between the two countries have not been very successful, and despite to initial expectations, commonalities have not become a success for Iran in achieving its goals, in a way that we can even speak of Iran's failure to achieve its objectives in relation to Azerbaijan. In explaining the reasons for these failures, this paper explains the attempts of Turkey to influence more on the developments in the region in the economic, political, and cultural areas, and tries to answer how objectives, interests, and policies of Turkey in the region have been effective in the failures of Iran.
\end{abstract}

Keywords: Iran, Turkey, Azerbaijan, South Caucasus, foreign policy, regional competition

\section{Introduction}

One of the most geopolitical developments in the last decades of the last century was the collapse of the Soviet Union. The consequence was the emergence of new independent states of the Caucasus and Central Asia and their entry into the arena of international relations. Accordingly, a new order came after the Cold War, which changed both the regional and international environment. Rich energy resources, consumer markets for investment, along with identity and social crises, structural and political crisis, and economic weakness and inefficiency of local governments are the agents, which attracted other global players in the region. One of the consequences, along with the competition of trans-regional powers was the activation of regional powers to be present and influence on the Central Asia and the Caucasus region, which prior to this, they were not able to play a major role, because of the Soviet Union. According to many experts, the main area of competition among regional powers is between Iran and Turkey (Rafi \& Mazloomi, 2012: 80). In fact, by the collapse of the Soviet Union and the emergence of independent states, Iran and Turkey took the opportunity to explore new economic and political roles in the region. By the cultural, religious, political and security reasons, Azerbaijan has always been a top priority of foreign policy of Iran in the Caucasus. Although Azerbaijan has common history, a common religion, common soil and water borders, a common language with a large minority of people of Iran, and in the past was a part of Iranian territory, Azerbaijan's relations with Iran have not developed in nearly two decades, and in some eras have faced serious crises.

Iran has defined a numerous goals and interests in the Caucasus and Central Asia, such as setting the legal regime of the Caspian Sea, using the primary resources and raw materials of the region, trying to convince neighboring countries to choose Iran as the path of energy transmission lines, preventing others from encroaching oil resources in the Caspian region, influencing the Muslims of Azerbaijan by religious and historical commonalities, preventing the formation and strengthening of political-security alliances, which are in the opposite direction with Iran, and finally neutralizing the U.S. and Israel presence and influence in the region. Achieving these goals largely depends on the development of political, economic, security, and cultural 
relationships with Azerbaijan. Many factors, both at the regional and trans-regional levels were influential, which each one has played a significant contribution to the failure of Iran. It appears one of the important factors is Turkey's efforts to influence the developments in the region in the economic, political, and cultural areas. These efforts have so far managed, directly or indirectly, the failure of Iran's politics in achieving its goals in the South Caucasus region, and particularly Azerbaijan. So that with a glance at the benefits and interests of Iran in the Caucasus, this failure can be realized.

In the present paper, researchers have attempted to answer how the objectives, interests, and policies of Turkey in the Caucasus in general, and The Republic of Azerbaijan in particular have been effective in the failure of Iran in the region. In this context, after considering the challenges in the areas of development of relations between Iran and Azerbaijan, Turkish foreign policy in the South Caucasus has been evaluated, and then the importance and opportunities of relationships between Turkey and Azerbaijan will be discussed. Finally, in the competition between Iran and Turkey, the factors and conditions which contributed to Turkey to be more successful in achieving its goals and interests, and caused the failure of Iran will be discussed.

\section{Challenges in Azerbaijan-Iran Relations since the Independence of Azerbaijan}

Challenges in relations between Iran and Azerbaijan took shape immediately after the country's independence and Nagorno-Karabakh crisis. Iran, first and foremost because of its security interests in the South Caucasus region in ensuring the security of its northern borders with Azerbaijan and Armenia (Maleki, 2007: 71) attempted to mediate in the crisis between the two countries. However, because of the unwillingness of major powers, especially Russia, Iran's mediation in regional peace became inconclusive. With the failure of peace negotiations, Azerbaijan accused Iran of supporting Armenia's involvement in the war of Nagorno-Karabakh. The issue of relations between Iran and Armenia has been causing the stir up sensitivity of Azerbaijan. Due to the geographical location of Armenia in accessing to European countries and also the role of Armenia as an effective actor in the South Caucasus region, Iran has always tried to improve its relations with Armenia (Ghysari, 2009: 130). On the other hand, due to the lack of natural energy resources, the lack of access to open water, the deep historical and ethnic disputes with other neighbors in its east and west, i.e. The Republic of Azerbaijan and Turkey, Armenia has been pushed toward Iran. Azerbaijan knows the ties of Iran with Armenia as an alliance of its enemies. This has always been overshadowed the bilateral relations of Iran and Azerbaijan.

The project of divided Azerbaijan into southern and northern has been an important factor in influencing the relationship of Tehran-Baku. Azerbaijan includes an Azeri-speaking population, which the larger part is located in Iran. This perception is at the heart of relations between the two countries. Maybe if Azerbaijan had another name, relations between the two countries would be further improved. The existence of Azerbaijan in the both sides of Aras River has been a motivation for Baku officials to have the dream of a united Azerbaijan. The idea was the ideals and aspirations of the leaders of Azerbaijan during the years before independence. In the summer of 1981, Heydar Aliyev as a member of the Political Bureau of the Communist Party of the Soviet Union, in the presence of a group of foreign diplomats, talked about the desire of Soviet Azerbaijan people for the unification of both parts. Such feelings intensified after the independence of Azerbaijan, and in the era of Ilchi Baig, which brought up the unification of both Azerbaijan with more heat, the idea reached to its peak. Such an idea, due to the kinship, religious, cultural, and language ties of Azerbaijani population in both sides of the Aras, brought some security concerns for Iran, and it has repeatedly condemned by Tehran.

Ideological conflict is one of the most divergent factors of the relationship between Iran and Azerbaijan. The ideological conflict and political perceptions of Iranian and Azeri activists, especially in government agencies creates a divergent structure in their bilateral relations. While the nature of the regime in Iran is Islamic, and the general direction of domestic and foreign policy is determined based on Islamic teachings, Azerbaijan's political system is a flexible model of western political systems focuses on the separation of religion and politics. Azerbaijan leaders are the former officials of the Communist Party who have not a positive attitude towards the role of religion in politics. The political system of the Republic of Azerbaijan sees the growth of political Islam as a threat to its existence. The overall difference between the nature of the political system of Iran (religious), and the political system of Azerbaijan (Secular) is a negative factor in the development of bilateral relations of both countries.

Issues of how to determine the legal regime of the Caspian Sea, and the share of each country, and also disputes between Iran and Azerbaijan in the energy field, and its transfer are other most important issues, which are the underlying disputes between the two countries since the first years after the founding of Azerbaijan (Blandy, 1998: 15). Definition of Azerbaijan on the Caspian legal regime offers that each country has its own share of Caspian Sea from the littoral zone to the central line - a line, which has equal distance from each beach. Iran's 
definition of the legal regime of the Caspian Sea is the opposite of the legal regime of Azerbaijan. Iran believes, by emphasizing on the need to respect the principle of fairness, a particular procedure should be used. In this method, it should be considered that any division or seabed division will not be viable regardless of the specific and influential features of geography of Caspian Sea, such as the shape of the coast, the length of the beach and other factors, such as the distribution of energy sources. To achieve a fair division, these features should be considered (Mirfakhrai, 2004: 180-188). It should be noted that differences in the legal regime of the Caspian Sea is not limited to Azerbaijan, and other countries of the Caspian Sea are also included. But due to joint oil and gas fields between the two countries, the differences are even greater.

Rejection of Azerbaijan in transferring its and other Central Asian republics' oil and gas through the pipeline that passes through the territory of Iran, and giving the privilege to Turkey is another reason that left a negative impact on relations between Iran and Azerbaijan. Not passing oil and gas pipelines of Central Asia and the Caspian Sea through Iran's route, both economically and politically causes some losses for Iran. If a short part of the route passed through the Iran's pipelines, given the need of the northern regions of Iran to oil, fuel supplies in these areas would be provided by buying and exchanging it. While oil and gas pipelines across a country is a sign of political stability and security, is also of a great importance for foreign investors. Moreover, political control privilege of pipelines for influencing on other countries was lost out of Iran's hand, and placed on the hand of Turkey.

Close ties of Azerbaijan, as the country which has the longest border with Iran in the Caucasus region, to the U. S. and Israel have also had negative effects on the country's relations with Iran (Koulai, 2010: 87). U. S. and Azerbaijan military cooperation increased the possibility of U. S. attack against Iran in a possible war using Azerbaijan's territory, and has aroused Iran's sensitivity towards their military relationships. By increasing pressure from foreign governments on Iran's nuclear stance, cooperation between the governments of Azerbaijan, United States, and Israel has grown. Confidential documents released by WikiLeaks on April 2011 disclosed that during the last 4 years Israel has been used the territory of Azerbaijan to spy on Iran. In addition to the items listed, deploying American missile defense shield in Azerbaijan, and the readiness of the Azerbaijani government to accept MKO members, if deported from Camp Ashraf, Iraq.

The foregoing issues leads the two countries to a divergence. Being aware of the challenges of bilateral relations between both countries, in an effort to develop theirs relations with Azerbaijan, other powers benefit from divergent components of both countries to put Iran aside of competing for influence on the region. Turkey is one of the most powerful countries in the region, which due to its language and cultural affinity with the Republic of Azerbaijan takes advantage of these components to influence the region, which will be discussed below.

\section{Principles, Objectives, and Interests of Turkish Foreign Policy in the South Caucasus}

In examining the foreign policy of Turkey in the South Caucasus, especially Azerbaijan, and its impact on the Azerbaijan-Iran relations, it is necessary to divide its foreign policy into two parts. The era before the AKP came to power, in which Kemalist policies guided the foreign policy of this country, and the rise to power of the AKP since 2002 in which the foreign policy has been based on new principles, and in academic circles is remembered as a neo-Ottomanism (Taspinar, 2011). Turkish foreign policy principles derived from Kemalist westernism policy in the Turkish constitution of 1937 was based on the following six principles: 1. Nationalism, 2. Secularism, 3. Republicanism, 4. Populism, 5. Statism, and 6. Reformism. These features first led to Turkey's resignation of regional issues, and secondly, became close to the West to exploit the country's economy due to some needs such as modernization, (Baran, 2010: 106-107) and strive to be recognized as a European nation, and be accepted in the Western Civilization (Omidi \& Rezai, 2011: 236-237). Turkey's special look to the West caused its foreign policy about the region to be of secondary importance. Only after the end of the Cold War and the emergence of Turkic-speaking countries in Central Asia and the Caucasus, some of the Kemalists, considering a shared history, culture and language with these countries sought a Pan-Turkism based on the teachings of Eurasianism to replace Kemalist teachings in the interaction of Turkey with the surrounding region (Aras, 2009: 67). Following this policy, Turkey sought to create an alliance of Turkic-speaking countries in Central Asia and the Caucasus to achieve this important. Pursuing this policy coincided with the rise of the Islamists and finally the rise of the AKP, and therefore a new discourse on domestic and foreign policy of the country formed. By the rise of the AKP, a contrast between the Islamist approach and Kemalist approach was expected in the politics of Turkey. However, in practice, the political climate in this country advanced into partnership (Robis, 2007: 289).

The most important component of Turkey's new foreign policy is a balanced foreign policy. Uniform and static foreign policy limits the opportunities of Turkey in the new world order. Hence, Turkey needs to diversify its 
policies, and should play a more active role in managing the regional crises, and also reduces foreign interventions in the region. Therefore, first, the country must put aside its old approach, which was it was surrounded by enemies, and must rebuild its relations with its neighbors. The main foreign policy objective of the country is establishing a stable region around. Nullifying the problems with neighbors is based on some core principles include 1. Equal security for all, 2. Economic integration, 3. Coexistence of different cultures, 4. High political participation, and 5. Understand the relationship between security, stability and development (Yesiltas, Balci, 2013: 13-14). The application of Davutoglu's doctrine in the practical Turkey's foreign policy led to the development of relations with neighboring countries vigorously.

Therefore adopted a new foreign policy, emerging Turkey's place in the world fundamentally changed in comparison to the Cold War times. The state of a buffer zone during the Cold War has become a state that looks back to its past glory, and looks into future for achieving a favorable position in the new order (Aktas, 2010: 1-2). Dramatic changes in the global, regional and domestic areas in the past two decades have changed Turkey's position from a backward country, which has a strategic importance for the West to a regional power with ambitious intentions in the Middle East, Central Asia and the Caucasus. In fact, by the collapse of the Soviet Union and the emergence of independent states in Central Asia and the Caucasus, Turkey was given an opportunity to explore new economic and political role in the region (Rafi \& Mazloumi, 2012: 81). Turkey's redefining of its history and geography as an energy center - which connects the Caucasus to Europe, relates the energy and the economy of the region with the global economy, and its strategic position - has affected the peace and stability of the region (Kardas, 2011: 58). Relations with the countries in the Caucasus, especially Azerbaijan is important for Turkey the same size as the country's relations with other countries in the Middle East and the Muslim world. It is currently believed that Turkey rather than a mediator, due to its linguistic and cultural affinity with the region sees itself as the central country in the region, and designs and implements its policies on these grounds (Davutoglu, 2008: 78).

Azerbaijan is of particular importance for Turkey because of its cultural and language proximity, and its significant energy resources. Ankara's policy about Baku is developing political and economic relations, and help them to develop mechanisms for considerably rising domestic stability, prosperity, security and peace. One of the mechanisms of influencing and managing region for Turkey is first, the formation of regional organizations such as the Organization of Black Sea cooperation and TRACECA in the framework of common economic and security interests (Solat, 2012: 4). As Azerbaijan has been seeking to reduce its dependence from Russia, and is also seeking a closer relationship with European Union, and its membership, Turkey always supports the corridor of East to West (TRACECA Passage), which its sponsor is the European Union, and is a way to transport energy resources of the Caspian Sea and Central Asia to Europe. Secondly, Turkey has tried, using the capabilities of NATO to provide military and security services for Azerbaijan. Being aware of the need of Baku to new security umbrella after the Soviet collapse, as well as emerging and presence as an established international player, Turkey has attempted to resolve crises, and tensions in the region around Azerbaijan (Solat, 2012: 5). However, despite the presence, Turkey considers wider influence on Azerbaijan, in the field of economic, energy, politics and military.

Azerbaijan's relative isolation from world markets, and its enclosed location prevent the export of its natural resources. By increased production and new mining, Azerbaijan needed new directions to take its natural products and the Caspian oil and gas to global markets (Kibarouglu, 2008: 119). Azerbaijan's solution to get out of this situation was to create new oil and gas pipelines, which was also supported by Western countries. Baku Tbilisi - Ceyhan Oil pipeline, and Baku - Tbilisi - Erzurum natural gas pipeline were the projects, which made important relations between Turkey and Azerbaijan in the realm of energy system. Baku - Tbilisi - Ceyhan Oil pipeline is $1,800 \mathrm{~km}$ long, and the construction cost is estimated about $\$ 2.4$ billion. The pipeline began operating in 2006, which ends in the Mediterranean coast of Turkey. The pipeline transfers more than one million barrels of oil a day (Bilgin, 2011: 405). More than being used for the purpose of economic growth, the pipeline follows a complex political goals. This project generates income for the countries involved, especially Azerbaijan. Turkey believes that this project has a great importance in the country's foreign policy strategy. The pipeline is a sign of economic integration between Turkey and the Turkic-speaking countries of the region. As well as the cooperation of Turkey and European Union in this project can speed up the membership of the country in Europe.

Azerbaijan's natural gas has entered Turkey through the Baku - Tbilisi - Erzurum pipeline since 2007, and through the period of validity of the agreement, which is 15 years, Turkey receives 6.6 billion cubic meters of natural gas from Shah Denizl field in Azerbaijan. Azerbaijan also attempts to meet the requirements of Nabucco Company from Shah Deniz 2 field by 2016. Nabucco plan was considered to transport gas from Turkmenistan, 
Iraq, Azerbaijan Republic, and potentially Iran to Turkey, and then from Turkey to Bulgaria, Romania, Hungary, and finally to Austria. The pipeline has shifted its focus on the transferring of the Caspian resources. In July 2009 the European countries involved in the pipeline plan signed an agreement in Ankara (Solat, 2012: 4-5). However, this plan has not yet taken its final form, because there is no final agreement between Turkey and Azerbaijan on the running of the plan, and because of lack of gas resources caused by the pressures of the U. S.to abandon Iran from it.

\section{Ideological Competition between Iran and Turkey in the South Caucasus}

After the collapse of the Soviet Union and the created ideological vacuum, one of the main objectives of Iran and Turkey in the Caucasus was to provide a viable alternative to the socialist model, which had lost its credibility. In this context, cultural characteristics, along with geographic location of the nascent states of the region on one hand, and the seriousness of Iran and Turkey immediately after the countries' independence on the other hand, uncertainties were added to ideological differences between Islamism and secularism in this area (Rafi \& Mazloumi, 2012: 88). Formation of a new great game in the region was due to two main characters, Iran and Turkey. Iranian knew itself as the representative of Islamists and their religious values, and on the opposite side Turkey was the representative of secularism, democracy, and free market economy (Hunter, 2003: 133). Turkey, to stop Iran's influence on the region, has always been concerned about Iran to play a role as an ideological influence on the region, and by magnifying the danger of Islamic fundamentalism sought to gain the attention of the South Caucasus' countries, especially Azerbaijan, that the development of Islamism in the region causes the instability of the political regimes. Turkey that saw itself as an important players in the equations of the South Caucasus, tried to influence regional developments, and attempted to unite the countries of the region, especially Azerbaijan. In this way, Turkey was sensitive to any rapid revolutionary developments in Azerbaijan, and strongly supported the status quo in this country. Policy of promoting pan-Turkism before the AKP, and providing specific governance model in Turkey after the AKP came to power is one of the Turkey's tools in order to avoid the influence of Iran's politics on the region. With the proliferation of pan-Turkism, Turkey was looking for evoking sentiments of the people of Azerbaijan and influencing them. In this regard, Turkey established schools, authored textbooks, and awarded scholarships to students of Azerbaijan to be more and more influential in the country. However, with the rise of the AKP, the country is trying to show itself as a Muslim country with the ability to adapt the Western values and liberal democracy.

After the collapse of the Soviet Union, Iran sought to play a decisive role in the Caspian littoral states. This, if successful, facilitated the promotion of international standing of Iran, and provided the exclusion of its isolation. Overall, Iran adopted major political approaches, which primarily was cultural and ideological influences (Chaboki, 2012: 68). In this ideological competition, Iran adopted a pragmatic approach, and with supporting the Muslim peoples of the region, and the spiritual and financial aid to religious institutions, and training seminary students tried to influence the area. Azerbaijani people welcomed the Shia teachings, and expressed interest to Iranian clergymen. At first Iranian authorities concluded that the considered ground for the spread of Islam and the religious teachings of the regime was provided. Iran hoped that the Muslim people of the Caucasus region, including Azerbaijan be interested in the establishment of an Islamic state. In this regard, this attempt would not be accepted by the conservative governments of the region. Thus, while it was expected that Shia doctrine be welcomed in Azerbaijan, due to its majority Shiite population, Turkey and the West announced the model of secularism and pan-Turkism, as an ideal example of modern secular democratic state. Due to the proximity of the Turkish language and culture, and support of the western states of the country, and Azerbaijan's necessity to this support, Turkey's model win the game in Azerbaijan (Chaboki, 2012: 69).

\section{Economic Competition between Iran and Turkey in the Region}

The economic competition between Iran and Turkey is the most obvious form of conflict between the two countries in Central Asia and the Caucasus. Competition in the oil and gas transmission pipelines, trades, and investments are the main areas, in which the economic relations between Iran and Turkey has formed in the south of Russia. What is the significance of the region is that there are large reserves of oil and gas in the Caspian Sea basin, which make the lake turned into a "second" Persian Gulf. Due to the lack of access to open water, Azerbaijan has caught within its environment. Azerbaijan faces Iran on the south side, Armenia on the west side, Russia and Georgia in the north, and the Caspian Sea as a natural obstacle on the east side of itself. The lack of a specific legal regime, a shared vision, and also the lack of a juristic organization for a large communication between the coastal zone's countries impose a sense of isolation and separation on Azerbaijan (Seydi, 2009: 75-76).

The conditions for the two countries, Iran and Turkey resulted in severe economic competition. The main 
competition is related to oil and gas reserves, and in particular the construction of transmission lines. In this regard, south route of Caspian energy transit passes through and is supported by Iran. In respect of the safety, route length, and investment costs for pipeline and transit lines, this route is more attractive and more advantageous in comparison to other pathways for energy transfer of the region. This route can take the energy resources of the Caspian Sea, and particularly Azerbaijan's to the Persian Gulf's markets, Sea of Oman, and from there to the rest of the world markets. Iran's gas pipe network is connected to the Azerbaijan, and is located in a short distance of the Republic of Turkmenistan. The pipeline which connects Republic of Kazakhstan and Turkmenistan to the network is at least four times shorter and cheaper than any other pipeline that should be constructed to the Black Sea and the Mediterranean Sea. The proposed networks must pass through mountainous and rocky areas, or through various armed politico ethnic groups, which have struggle with themselves or with regional governments. These issues minimize the essential security for the pipe network.

On the other hand, by emphasizing on the support of the U. S., and by being aware of Azerbaijan's western tendency, and its tendency to use energy transfer pathways using any country other than Iran, and also its new energy policies, Turkey has tried to propose alternative routes, which all pass through its own land (Kardas, 2013: 56). Although the governments of Ankara and Baku have never opposed to any pipeline that connect Central Asia and Caucasus from Iran to Turkey, consistency with the interests of Western governments forces the authorities of both countries to show a greater tendency to alternative routes. (Seydi, 2009: 76). Transportation of oil and gas of the region through any other way than Iran's, also curtails the opportunities for competition, and allows Turkey to proceed to have significant and decisive role in political and economic life of the new independent states. Baku - Tbilisi - Ceyhan, and Baku - Yerevan - Ankara routes are the lines opposite to the proposed routes of Iran to transport Azerbaijan and the Caspian Sea oil, and are supported by the U. S. and Turkey at the same time (Rafi, Mazloumi, 2012, 93).

Structural reforms that Turkey and Iran had in the early and late 1980s, respectively in their macro-economic trends towards export-based development led to obtaining desirable and favorable markets of foreign countries to become an inevitable necessity. Accordingly, based on their quality of the goods, untapped market of Azerbaijan was precious for both countries. After the collapse of the Soviet Union, Turkey sent a large group of political, cultural and economic experts, and a large group of merchants to the newly independent republic to carefully consider their business facilities. Following that, a torrent of Turkish products were flooded to the regional markets, and the process still continues. Business statistics between 2000 and 2006 indicated that Turkey's exports to Azerbaijan has tripled in recent years. This represents a growth rate of exchanges between the two countries (Dikkaya \& Ozyakisir: 2008: 111). Iran would also signed commercial agreements with Azerbaijan, and by some actions tries to develop its business relationships with regional countries. Iran and Turkey are in strong competition with each other over the road lines, the communication networks, and transportation routes from Central Asia to the rest of the world, as well as investment opportunities in the region. In this regard, Turkey has taken a more practical steps even by the creation of new institutions including the Turkish International Cooperation Agency, or the Export-Import Bank of Turkey, and infrastructure projects such as telecom Turkcell company, and construction companies (Guney \& Ozdemir: 2011: 135). Turkey currently has more than 200 economic, cultural, training, and communicating agreements with Central Asia and the Caucasus countries. On the other hand, the Islamic Republic of Iran, to a lesser extent and according to its economic capacity has tried to take advantage of investment opportunities in the region. An example would be to create a joint shipping company in the Caspian Sea with the effective participation of Iran with the Republic of Azerbaijan, or joint projects in the fields of engineering, light industry, food industry, and agriculture sectors. In general it can be said that Turkey's economic policy in Central Asia has been more successful than Iran. Turkey's relative economic advantages in the region could be because of economic superiority over Iran's economy, financial and political support from the West, external requirements and cultural factors, and the failure of the domestic economy of Iran due to its previous war and its domestic situation. In this regard, what is clear is that the rivalry between Turkey and Iran over Azerbaijan's interests and markets is more dependent on the private capitals.

\section{Conclusion}

The collapse of the Soviet Union and the formation of new political, economic, and security opportunities in the Caucasus, and simultaneously attempts of both Turkey and Iran to become the most important and influential regional actor have caused Turkish-Iranian relations in the region tend to have a confrontation and competition since the early history of the region's nascent states. Rivalry between Iran and Turkey in the region is more based on the three main aspects of the ideological, political, and finally economic competitions, which are crystallized and focused. Much of Turkey's actions in the South Caucasus region, particularly in relation to Azerbaijan is not 
in oppose to the interests of Iran, but due to its Eurasian centrality and regionalism in the country's foreign policy, and the benefits and opportunities that arise in this area. On the other hand, ideological and political problems and conflicts between Iran and Azerbaijan, immediately after its independence, also urged will of regional and trans-regional actors like Russia and Israel, or policies of the West, particularly the United States against Iran's influence in Central Asia and the Caucasus caused the failure of Iran in the region. According to public and private sector's economic weaknesses for financial, economic, and industrial investments, Iran has lost its ability to compete effectively and to influence and negotiate in the region. Affected by the obstacles created by the West, and due to the results of sanctions against Iran, Turkey has been able to strengthen its influence on the region. Given the challenges between Iran and Azerbaijan, Turkey has also been able to outshine the ideological and economic competition, and build stronger relations with Azerbaijan.

\section{References}

Aras, B. (2009). Turkey and the Russian Federation: An Emerging Multidimensional Partnership. SETA Policy Brief, No. 35. Retrieved from http://www.setav.com

Baran, Z. (2010). Torn Country: Turkey between Secularism and Islamism. Stanford: Hoover institution press.

Bilgin, M. (2011). Energy in Turkey: Security, Markets, Supplies and Pipelines. Turkish Studies, 12(3), 399-417. http://dx.doi.org/10.1080/14683849.2011.604209

Blandy, C. W. (1998). The Caucasus Region and Caspian Basin: Change Competition and Challenge. Conflict Studies research, 36, 1-28.

Chaboki, O. (2011). The Impact of United States Presence in Caspian Sea Region over Iran Interests. Policy Quarterly, 41(3), 57-76.

Davutoghlu, A. (2008). Turkey's Foreign Policy Vision: An Assessment of 2007. Insight Turkey, 10(1), 77-96.

Dikkaya, M., \& Ozyokisir, D. (2008). Developing Regional Cooperation among Turkey, Georgia and Azerbaijan: Importance of Regional projects, Perceptions, Spring-Summer 2008, pp. 93-118.

Elahe, K. (2010). Iran and South Caucasus Geopolitics. Geopolitics Quarterly, 6(1), 75-111.

Ghysari, N., \& Goudarzi, M. (2009). Iran and Armani Relationship: Opportunities and Obstacles. Central Eurasia Studies, 2(3), 121-144.

Guny, A., \& Ozdemir, S. (2011). Is the Regional Economic Cooperation in South Caucasus Myth or Reality? Journal of Faculty of Economics and Administrative sciences, 16(1), 133-145.

Hunter, S. (2003). Iran's Pragmatic Regional Policy. Journal of International Affairs, 56(2).

Ipek, P. (2008). Azerbaijan: Oil Boom and Challenges. In M. Kibarouglu (Ed.), Turkey's Neighborhood. Foreign Policy Institute. Retrieved from http://www.foreignpolicy.org.tr

Kardas, S. (2011). Turkish - Azerbaijani Energy Cooperation and Nabaco: Limits of the New Turkish Foreign Policy Rhetoric. Turkish Studies, 12(1), 55-77. http://dx.doi.org/10.1080/14683849.2011.563503

Maleki, A. (2007). Iran's New Asian Identity. In A. Novikova (Ed.), Regional Security Issues: 2007. Yerevan: Amrost Group.

Mirfakhrai, S. H. (2004). Caspian Sea Legal Regime, From Divergence to Convergence. Law and Politics Studies, 10, 179-200.

Omidi, A., \& Rezai, F. (2011). Neo-Ottomanism in Turkey New Foreign Policy: Characteristics and Effects on Middle East. Foreign Policy Quarterly, 3(3), 231-267.

Rafi, H., \& Mazloumi, I. (2012). Obstacles toward Cooperation of Iran and Turkey in Central Asia and Caucasus. Central Eurasia Studies, 5(10), 79-98.

Robins, P. (2007). Turkish foreign policy since 2002 between a past - Islamic government and Kamalist stats. International Affairs, 83(2), 289-304. http://dx.doi.org/10.1111/j.1468-2346.2007.00619.x

Sadegh-Zadeh, K. (2008). Iran's strategy in the south Caucasus. Caucasian Review of International Affairs, 2(1), $1-7$.

Seydi, M. (2009). Republic of Azerbaijan Geopolitical Factors and its Impact on Iran National Security. Central Asia and Caucasus Quarterly, 65, 71-89.

Solat, R. (2012). The Republic of Azerbaijan, The Land of Opportunity and Interest for Turkey. Tehran: Abrare Moaser. 
Taspinar, O. (2011, March 8). The Three Strategic Visions of Turkey. US - Europe Analysis Series, 50.

Yelken Aktas, G. (2010). Turkish Foreign Policy: New Concepts and Reflections, Unpublished Master Thesis, Middle East technical university, Ankara.

Yesiltas, M., \& Balci, A. (2013, May). A Dictionary of Turkish Foreign Policy in the AK Party Era: A Conceptual Map. Center for Strategic Research, 7.

\section{Copyrights}

Copyright for this article is retained by the author(s), with first publication rights granted to the journal.

This is an open-access article distributed under the terms and conditions of the Creative Commons Attribution license (http://creativecommons.org/licenses/by/3.0/). 